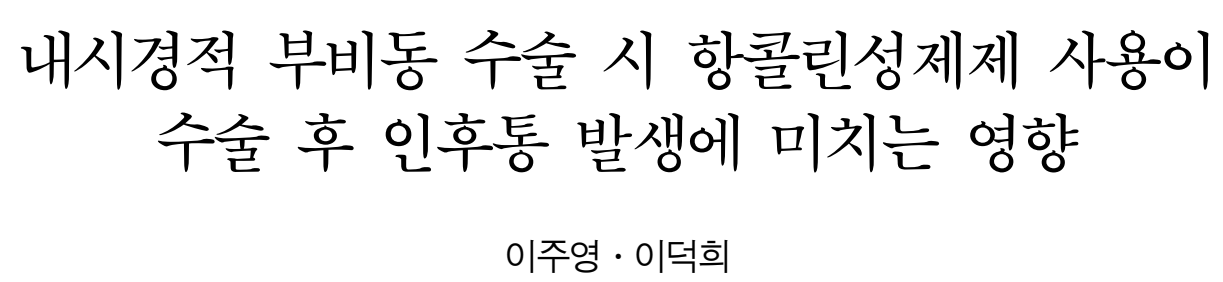

영남대학교 의과대학 마취통증의학교실

\title{
The Effect of Anticholinergic Agents on Postoperative Sore Throat in Patients Undergoing Endoscopic Sinus Surgery
}

\author{
Joo Young Lee, Deok Hee Lee \\ Department of Anesthesiology and Pain Medicine, \\ College of Medicine, Yeungnam University, Daegu, Korea
}

\section{- Abstract-}

Background: After sinus surgery, airway dryness is made worse because patients breathe by mouth. Anticholinergic agents have antisialogogue effects. The airway dryness that occurs after surgery is severe and can increase the incidence of postoperative sore throat.

Materials and Methods: One-hundered patients who were scheduled for endoscopic sinus surgery(ESS) were divided into four groups. Each group was premedicated with glycopyrrolate or had no premedication and reversed with glycopyrrolate or atropine. After the surgery the patients were asked about a sore throat and hoarseness postoperatively after $1 \mathrm{~h}, 6 \mathrm{~h}, 12 \mathrm{~h}, 24 \mathrm{~h}$, and 48hours, respectively.

Results : The incidence of postoperative sore throat and hoarseness was not significantly different among the four groups at any time.

Conclusion : The severity of complications after ESS was low and subsided within 24 hours. Therefore, the use of anticholinergic agents does not need to be limited.

Key Words: Anticholinergic agents, Throat complication

책임저자 : 이덕희, 대구광역시 남구 대명5동 317-1번지, 영남대학교 의과대학 마취통증의학교실

Tel: (053) 620-3368, Fax: (053) 626-5275, E-mail: dhlee415@ynu.ac.kr 


\section{서 론}

전신 마취 시 기도삽관 후에 생기는 인후통 과 쉰 소리는 술 후 통증이나 구토 등에 비하 면 사소한 합병증이라 할 수 있으나 환자들이 흔히 호소하는 불편함이다. 술 후 인후 합병증 을 유발하는 인자로는 아산화질소 사용, 높은 기낭압력, 큰 기관 튜브나 튜브 윤활제 사용, succinylcholine 사용 등이 있다. ${ }^{1,2)}$

항콜린성 제제인 glycopyrrolate는 atropine 이나 scopolamine보다 상기도 분비억제작용은 강력하나 빈맥이나 중추신경계작용은 거의 없 어 흔히 쓰이는 마취 전투약제로서 근주 시 6 8시간, 정주 시 2 4시간의 긴 작용시간을 가지고 있다. Atropine은 근주 시에 상기도 분비억제 작용이 약하고 작용시간은 $2 \sim 4$ 시 간이다. 작용 시간을 비교하여 볼 때 atropine 에 비하여 glycopyrrolate는 상대적으로 긴 작 용시간을 가지고 있다. 마취 전투약제로서 glycopyrrolate의 사용은 상기도의 점막을 건 조하게 하여 기관내 삽관 시 손상을 줄 가능 성이 있으며, 긴 작용시간으로 술 후에도 구강 건조를 일으켜 인후 합병증의 발생을 높일 수 있다. ${ }^{3-5)}$

내시경적 부비동 수술은 수술시간이 대략 1 시간 내외로 짧고, 수술 후 양 코를 막는 경우 입으로 숨을 쉬게 되어 구강건조가 심해져 상 기도 분비억제작용이 약한 atropine 사용 후 보다 glycopyrrolate 사용 후 인후 합병증이 더 많을 것으로 예상된다. 따라서 이 연구에서는 내시경적 부비동 수술을 받는 환자에서 항콜린 성 제제사용이 술 후 인후 합병증에 어떠한 영 향을 미치는지 보고자 하였다.

\section{대상 및 방법}

내시경적 부비동 수술이 예정된 14 65세 ASA (American Society of Anesthesiologists) I, П에 속하는 환자 100 명을 대상으로 하였다. 이미 인후통이 있거나 역류성 위염의 병력, 기 관내 삽관 시 기침요동이 있는 경우, 발관 전 기침요동이 있는 경우, 어려운 기관 삽관, 외상 성의 기관 삽관, 술 후 구토의 경우는 제외하 였다(Table 1). 환자를 임의로 각 네 군으로 25명씩 나누어 glycopyrrolate를 전투약 하고 반전시에 쓴 군(1군), 전투약을 하지 않고 반 전에만 쓴 군(2군), 전투약에만 쓰고 반전은 atropine을 쓴 군(3군), 전투약을 하지 않고 반 전은 atropine으로 한 군(4군)으로 나누었다. 마 취 전투약은 수술 시작 전 30분에 근주 하였다.

마취 전투약은 수술 시작 전 30분에 근주 하 였다. 모든 환자는 마취유도를 하기 전에 심전 도, 혈압, 심박수, 경피적 산소포화도를 감시하 고 $\mathrm{BIS}$ 측정을 시작하였다. 마취유도는 propofol 정주 시 통증 감소를 위하여 lidocaine $0.5 \mathrm{mg} / \mathrm{kg}$ 를 정주한 뒤 propofol $1.5 \sim 2 \mathrm{mg} / \mathrm{kg}$ 를 정주하 고 의식 소실 후 근 이완을 위하여 rocuronium bromide $1 \mathrm{mg} / \mathrm{kg}$ 를 정주 하였다. 기관내 삽관 시 튜브 윤활제 사용이나 lidocaine 분무는 하지 않았다. 삽관 튜브는 여자 환자에서 내경 $7.5 \mathrm{~mm}$,

Table 1. Exclusion criteria

Preexisting sore throat

History of gastric reflux

Coughing or bucking on intubation

Coughing or prior to extubation

Difficult or traumatic intubation, reintubation Intraoperative bucking

Postoperative vomiting 
Table 2. Patient characteristics

\begin{tabular}{lcccc}
\hline & G1 $(\mathrm{n}=25)$ & G2 $(\mathrm{n}=25)$ & G3 $(\mathrm{n}=25)$ & G4 $(\mathrm{n}=25)$ \\
\hline Sex $(\mathrm{M} / \mathrm{F})$ & $19 / 6$ & $18 / 7$ & $19 / 6$ & $17 / 8$ \\
Age $(\mathrm{yr})$ & $39.2 \pm 12.3$ & $35.9 \pm 15.2$ & $34.6 \pm 9.6$ & $34.1 \pm 10.9$ \\
Weight $(\mathrm{kg})$ & $67.5 \pm 11.6$ & $66.7 \pm 11.0$ & $70.7 \pm 12.8$ & $65.0 \pm 10.5$ \\
Height $(\mathrm{cm})$ & $169.2 \pm 7.1$ & $169.5 \pm 7.7$ & $170.4 \pm 7.5$ & $169.5 \pm 9.5$ \\
Op.time (min) & $51.3 \pm 13.5$ & $44.0 \pm 18.5$ & $43.2 \pm 13.9$ & $45.2 \pm 15.5$ \\
Anes.time (min) & $73.2 \pm 14.3$ & $73.2 \pm 18.8$ & $69.4 \pm 15.2$ & $74.9 \pm 18.8$ \\
\hline
\end{tabular}

Values are mean \pm SD. G1: glycopyrrolate premedication, glycopyrrolate reverse. G2: no premedication, glycopyrrolate reverse. G3: glycopyrrolate premedication, atropine reverse. G4: no premedication, atropine reverse. Op: operation. Anes: anesthesia

남자 환자에서는 $8.0 \mathrm{~mm}$ 의 Armored tube를 사 용하였고 기낭 압력은 공기누출이 들리지 않을 때까지 가압하고 기낭 압력을 $20 \mathrm{cmH}_{2} \mathrm{O}$ 이하 로 유지하였다. $\mathrm{O}_{2} / \mathrm{N}_{2} \mathrm{O}$ 를 유량 각각 $1.5 \mathrm{~L} / \mathrm{min}$ 으로 하여 호기말 이산화탄소 분압은 30 35 $\mathrm{mmHg}$ 가 되도록 일회 호흡량과 호흡수를 결 정하였다. 마취유지는 propofol과 remifentanil 의 지속주입으로 유지하였다. 지속주입은 목표 조절농도주입장치를 이용하였고 수술 중 각성 예방을 위하여 BIS 수치를 감시하여 40 50으 로 유지하고 혈압유지를 위해 propofol은 2.0 $3.5 \mu \mathrm{g} / \mathrm{ml}$, remifentanil은 $0.05 \sim 0.2 \mu \mathrm{g} / \mathrm{ml}$ 로 농도를 조절하였다. 수술 중 기침요동 예방을 위 해 근 이완 감시 장치로서 신경근 전달 감시 장치를 이용하여 사연속자극(TOF, train of four)
에 1 개의 연축 반응이 나타날 때 rocuronium bromide $0.2 \mathrm{mg} / \mathrm{kg}$ 를 추가 투여하였다. 발관 시에는 지속주입을 수술 종료 2분전에 중지하 고 산소만 흡입시켜 사연속자극 비율이 $70 \%$ 이상일 때 반전 하고 $\mathrm{BIS}$ 를 감시하여 수치가 80 이상일 때, 환자가 자발적으로 각성하고 자 발 호흡이 규칙적이고 일회 호흡량이 충분할 때 발관하였다.

마취 종료 후 1 시간, 6시간, 12시간, 24시간, 48시간에 환자를 직접 방문하여 인후통과 쉰 소리 유무를 질문하여, 인후통의 경우에는 없 는 경우 0 , 있는 경우에 감기 시 목 아픈 것 보다 약하면 1 , 비슷하면 2, 더 심하면 3으로 하여 심각도를 나누어 물었다.

각 군 간의 인구통계학적 자료의 비교에는

Table 3. Sore throat incidence

\begin{tabular}{lccccc}
\hline & G1 $(\mathrm{n}=25)$ & G2 $(\mathrm{n}=25)$ & G3 $(\mathrm{n}=25)$ & G4 $(\mathrm{n}=25)$ & $\mathrm{P}$ value \\
\hline S1 (\%) & $44 \%$ & $28 \%$ & $32 \%$ & $32 \%$ & 0.658 \\
S6 (\%) & $32 \%$ & $28 \%$ & $16 \%$ & $28 \%$ & 0.600 \\
S12 (\%) & $20 \%$ & $8 \%$ & $8 \%$ & $8 \%$ & 0.430 \\
S24 (\%) & $4 \%$ & $4 \%$ & $4 \%$ & $0 \%$ & 0.794 \\
S48 (\%) & $0 \%$ & $0 \%$ & $0 \%$ & $0 \%$ & - \\
\hline
\end{tabular}

S1, S6, S12, S24, S48: Sore throat postoperatively after 1h, 6h, 12h, 24h, 48h.

$\mathrm{P}$ value by $\mathrm{X}^{2}$-test between four groups. 
One-way ANOVA를 이용하였고, 각 군 간의 인후통 및 쉰 소리의 발생빈도 비교는 $\mathrm{X}^{2}$-test 를 이용하였다. $\mathrm{P}$ 값이 0.05 미만인 경우를 통 계적으로 유의한 것으로 간주하였다.

\section{결 과}

대상 환자의 나이, 체중, 신장, 수술시간, 마 취시간, 성별에는 네 군 간에 유의한 차이가 없었다(Table 2).

수술 1 시간 후의 인후통 발생률은 각각 1 군 에서 $44 \%, 2$ 군에서 $28 \%, 3$ 군과 4 군에서 $32 \%$, 술 후 6 시간째에는 32\%, 28\%, 16\%, 28\%, 술 후 12 시간째에는 $20 \%, 8 \%, 8 \%, 8 \%$, 술 후 24 시간째에는 4\%,4\%,4\%, 0\%였고 술 후 48시 간째에 인후통은 모든 군에서 없었다. 인후통 이 있는 경우 심각도는 모든 환자에서 1이었 다. 수술 후 1 시간, 6 시간, 12 시간, 24 시간의 인 후통 발생률은 $\mathrm{P}$ 값이 각각 $0.658,0.600,0.430$, 0.794로 네 군 간 통계적으로 유의한 차이는 없었다(Table 3).

쉰 소리는 모든 환자에서 발생하지 않았다.

\section{고 찰}

양 측 내시경적 부비동 수술 후에는 양 코 를 막아 입으로 숨을 쉬게 되어 전투약과 반전 에 쓰인 항콜린성 제제의 상기도 건조 효과와 더해져 수술 후 구강 건조가 심할 것으로 생각 하였다. 이 연구에서 1 군은 전투약과 반전 모 두에 glycopyrrolate를 사용하여 다른 군 보다 인후 합병증의 발생이 높을 것으로 예상하였으 나 술 후 1 시간째와 6 시간째 인후통 발생률은 다른 군보다 높지만 통계적으로 유의한 차이가
없었다. 술 후 인후통의 발생률은 다양하게 나 타났으나 심각도는 모두 1이하였으며 쉰 소리 는 전혀 없었다.

전신 마취 하 기관내 삽관 후 인후통은 30 $\%$ 60\%의 발생률을 보이고, 술 후 쉰 소리는 47\% 76\%의 높은 발생률을 보이는 합병증으 로 환자들이 흔히 불편함을 호소하며 따라서 이를 줄이기 위한 다양한 방법들이 연구되었 다. ${ }^{4-6)}$ 인후통의 발생에 영향을 미치는 인자로 는 아산화질소 사용, 높은 기낭 압력, 큰 기관 튜브, 튜브 윤활제 사용, succinylcholine 사용 등이 있다. ${ }^{1,2)}$ 그 외에 기관내 삽관 전 lidocaine 분무, 마취 유도 시 lidocaine 정주가 인후통 발생에 영향을 준다는 연구가 있다. ${ }^{3-7)}$ Maruyama 등5)은 clonidine 전투약 후 인후통 발생에 관 한 연구에서 clonidine을 전투약 한 경우 부교 감신경 억제효과로 인한 침 분비 억제 때문에 처치하지 않은 경우 보다 인후통의 빈도가 높 았다고 보고하였다.

침 분비 억제 효과가 있는 항콜린성제제 중 glycopyrrolate는 근주 시 빈맥이나 중추신경계 작용은 거의 없이 강력한 침 분비 억제 효과가 있는 반면 atropine은 빈맥을 일으키며 상기도 건조 효과는 정주 시에는 거의 없고 근주 시 에 약한 효과만 있다. Glycopyrrolate는 상기 도 분비억제 작용이 강력하여 상기도 건조를 유발하여 기관내 삽관 시에 건조한 상기도 점 막과 딱딱한 튜브의 접촉으로 상기도 손상을 줄 수 있다. ${ }^{3-5)}$ 또한 근주 시 6 8시간, 정주 시에는 2 4시간 정도의 긴 작용시간을 가지는 반면 atropine의 작용시간은 근주 시 2 4시간, 정주 시 15 30분이다. Glycopyrrolate는 이런 긴 작용시간을 보여 술 후에도 지속적인 상기 도 건조를 일으켜 인후 합병증을 악화시킬 수 
있다.

이 연구에서는 다른 요인으로 인한 인후 합 병증 발생을 배제하기 위하여 모든 환자에서 동일한 내경의 Armored 튜브를 사용하였고, 기낭압력을 일정하게 유지하기 위하여 압력측 정기를 사용하여 $20 \mathrm{cmH}_{2} \mathrm{O}$ 이하로 유지하였다. 수술 중 기침요동은 기도에 손상을 일으키므로 수술 중에 기침요동을 예방하고 일정한 마취 심도를 유지하기 위하여 BIS 감시장치를 사용 하고 사연속자극에 1 개의 연축반응이 나타날 때 근이완제를 투여하여 근 이완 상태를 유지 하여 수술 중 기침요동이 있거나 환자가 움직 이는 경우는 없었다. 다른 인자인 lidocaine의 조절에 관해서는 Takekawa 등ㄱㅇㅢ 연구에서는 기관내 삽관 5 분전 lidocaine $1 \sim 1.5 \mathrm{mg} / \mathrm{kg}$ 정 주 시 인후통의 발생이 적었다고 보고한 바가 있다. 이 연구에서는 마취 유도시 propofol 주사 전에 통증감소를 위하여 lidocaine $0.5 \mathrm{mg} / \mathrm{kg}$ 를 기관내 삽관 3 분전에 주사하여 lidocaine 정주 로 인한 효과도 배제하였다. 발관 시에는 기도 내 분비물 흡인 시 기침이 없고, BIS 수치가 80 이상이고 환자가 구두명령에 반응하여 눈을 뜰 때까지 기침한 경우는 없었다.

Stratelak 등은 glycopyrrolate 또는 meperidine 을 전투약한 경우 인후통의 발생을 비교한 연 구에서 glycopyrrolate를 사용한 군에서 인후통 의 발생이 유의하게 높다고 하였고, 심각도는 glycopyrrolate를 사용한 군에서 중등도 이상의 반응을 보인 환자가 $46.9 \%$ 로 높게 보고되었다. 그러나 이 연구와의 차이점으로서 시간을 정하 여 인후통에 대한 조사를 한 것이 아니라 수술 후 30시간 내 언제든지 인후통이 있었는지 조 사하였고, 마취깊이의 조절과 수술 중 기침요 동의 발생을 조절하지 않았다. 그에 비해 이
연구에서는 인후 합병증 발생률은 군 간의 차 이는 없었으나, 근 이완 상태를 수술 중 감시 하여 수술 중 기침요동이 있는 환자는 제외하 였고, 회복기 각성흥분을 보인 환자가 없어 마 취 시작부터 마취 회복기까지 기도 자극이 될 요인을 배제하였다. 또한 중등도 이상의 심각 한 인후통을 호소한 경우가 없었고 술 후 24시 간 후에는 각 군 발생률이 $4 \%, 4 \%, 4 \%, 0 \%$ 였 고 48 시간 후에는 네 군 모두 $0 \%$ 로 인후통은 발생하지 않았다.

결론적으로 술 후 인후통의 발생률은 $\mathrm{glyco}^{-}$ pyrrolate를 전투약하고 반전시에도 사용한 1 군에서 술 후 12 시간까지 다른 군보다 높아 glycopyrrolate 사용이 인후통 발생을 유발했을 가능성은 있으나 통계적으로 유의한 차이는 없 었다. 강력한 상기도 건조 기능이 있어 술 후 불편함을 줄 수 있으나 glycopyrrolate를 전투 약 하지 않은 경우 과도한 침 분비로 기관내 삽관 후 튜브 고정이 어렵고, 종종 수술에 방 해가 되기도 하였다. 인후통 발생은 그 심각도 가 낮고 24 시간 후에는 거의 없으며 쉰 소리는 발생하지 않아 양 측 내시경적 부비동 수술시 glycopyrrolate의 사용은 적절할 것으로 생각된다.

\section{요 약}

수술 후 인후 합병증은 통증이나 구토에 비 하면 사소한 합병증이지만 흔히 환자들이 불편 을 호소한다.

양 측 내시경적 부비동 수술 후에 양 코를 막아 입으로 숨 쉬게 되어 구강 건조가 더 심 할 것으로 보고 환자들을 glycopyrrolate를 전 투약 하고 반전시에 쓴 경우, 전투약 하지 않 고 반전에만 쓴 경우, 전투약에만 쓰고 반전은 
atropine을 쓴 경우, 전투약 하지 않고 반전은 atropine으로 한 경우의 네 군으로 나누었다. 마취 종료 1시간, 6시간, 12 시간, 24시간, 48시 간 후의 인후통과 쉰 소리 여부를 묻고, 없는 경우 0 , 있는 경우에는 감기 시 목 아픈 것 보 다 약하면 1 , 비슷하면 2, 더 심하면 3으로 하 여 심각도를 나누어 물었다. 각 군 간의 인후 통 발생률은 1 군에서 조금 높았으나 유의한 차 이가 없었다. 심각도는 모두 1이하로 낮았다. 쉰 소리는 모든 환자에서 발생하지 않았다. 양 측 내시경적 부비동 수술 후 인후 합병증은 심 각도가 낮고 24 시간 내에 사라지는 것으로 항 콜린성 제제 사용을 피해야 할 필요성은 없을 것으로 보인다.

\section{참 고 문 헌}

1. Mandoe H, Nikolajsen L, Lintrup U, Jepsen D, Molgaard J. Sore throat after endotracheal intubation. Anesth Analg 1992 Jun;74(6):897900.

2. Biro P, Seifert B, Pasch T. Complaints of sore throat after tracheal intubation: a prospective evaluation. Eur J Anaesthesiol 2005 Apr;22(4): 307-11.
3. Maruyama K, Sakai H, Miyazawa H, Iijima K, Toda N, Kawahara S, et al. Lar yngotracheal application of lidocaine spray increases the incidence of postoperative sore throat after total intravenous anesthesia. J Anesth 2004;18(4): 237-40.

4. Hara K, Maruyama K. Effect of additives in lidocaine spray on postoperative sore throat, hoarseness and dysphagia after total intravenous anaesthesia. Acta Anaesthesiol Scand 2005 Apr;49(4):463-7.

5. Maruyama K, Yamada T, Hara K. Effect of clonidine premedication on postoper ative sore throat and hoarseness after total intravenous anesthesia. J Anesth 2006;20(4):327-30.

6. Ayoub CM, Ghobashy A, Koch ME, McGrimley L, Pascale V, Qadir S, et al. Widespread application of topical steroids to decrease sore throat, hoarseness, and cough after tracheal intubation. Anesth Analg 1998 Sep;87(3):714-6.

7. Takekawa K, Yoshimi S, Kinoshita Y. Effects of intravenous lidocaine prior to intubation on postoperative airway symptoms. J Anesth 2006; 20(1):44-7.

8. Stratelak PA, White W, Wenzel D. The effect of glycopyrrolate premedication on postoperative sore throat. AANA J 1996 Dec;64(6):545-8. 